\title{
LAS REFORMAS INTRODUCIDAS POR LA LEY 26/2015, DEL 28 DE JULIO, EN MATERIA DE ADOPGIÓN EN EL CÓDIGO GIVIL ESPAÑOL
}

\author{
Abigail QUESADA PÁEZ*
}

SUMARIO: I. Introducción. II. La adopción. III. Conclusiones. IV. Bibliografia.

\section{INTRODUCGIÓN}

La ley Orgánica 1/1996, del 15 de enero, de Protección Jurídica del Menor de modificación parcial del Código Civil y de la Ley de Enjuiciamiento Civil, supuso un gran avance en la regulación de los derechos de los menores de edad en España, ya que se les garantizaba una protección uniforme en todo el territorio nacional, y se hacía en aras del cumplimiento del artículo 39 de la Constitución española. ${ }^{1}$

Veinte años después, desde la promulgación de la esta Ley, se hacía necesaria una reforma de la misma que se adecuara a las necesidades actuales de los menores de edad.

Con el fin de mejorar los instrumentos de protección jurídica de la infancia y la adolescencia y constituir una referencia para las comunidades autónomas en el desarrollo de su respectiva legislación en la materia,

* Profesora de derecho civil en la Facultad de Derecho, Departamento de Derecho Civil, Universidad de Granada (España) e.mail: aquesadap@ugres.

1 El artículo 39 de la Constitución establece:

1. Los poderes públicos aseguran la protección social, económica y jurídica de la familia.

2. Los poderes públicos aseguran, asimismo, la protección integral de los hijos, iguales éstos ante la ley con independencia de su filiación, y de las madres, cualquiera que sea su estado civil. La ley posibilitará la investigación de la paternidad.

3. Los padres deben prestar asistencia de todo orden a los hijos habidos dentro o fuera del matrimonio, durante su minoría de edad y en los demás casos en que legalmente proceda.

4. Los niños gozarán de la protección prevista en los acuerdos internacionales que velan por sus derechos.

Boletín Mexicano de Derecho Comparado, nueva serie, año L, núm. 151, enero-abril de 2018, pp. 395-410. 
se ha llevado a cabo una profunda reforma del sistema de protección de menores en España.

La Ley 26/2015, del 28 de julio, de modificación del sistema de protección de la infacia y adolescencia, y la Ley Orgánica 8/2015, del 22 de julio, de modificación del sistema de protección de la infancia y adolescencia, integran la profunda reforma realizada por el legislador español.

Como dice la exposición de motivos de la Ley 26/2015, del 28 de julio, el objeto de la ley es introducir los cambios necesarios en la legislación española de protección a la infancia y a la adolescencia, que permitan continuar garantizando a los menores una protección uniforme en todo el territorio del Estado, y que constituya una referencia para las comunidades autónomas en el desarrollo de su respectiva legislación en la materia. Además, y de modo recíproco esta ley incorpora algunas novedades que ya han sido introducidas por algunas normas autonómicas estos años atrás.

Las modificaciones de la Ley Orgánica de Protección Jurídica del Menor se refieren básicamente a la adaptación de los principios de actuación administrativa a las nuevas necesidades que presenta la infancia y la adolescencia en España, tales como la situación de los menores extranjeros, que son víctimas de violencia, y la regulación de determinados derechos y deberes. Por otra parte, se realiza una profunda revisión de las instituciones del sistema de protección a la infancia y a la adolescencia.

Podríamos decir que las modificaciones más importantes que introducen estas leyes son el interés superior del menor, derecho del menor a ser escuchado, deberes de los menores, reformas de las instituciones de protección a la infancia y a la adolescencia, importantes reformas en materia de adopción, medidas en materia de violencia contra los menores, menores con problemas de conducta, reformas procesales y menores extranjeros.

El objeto de este trabajo es centrarnos en las reformas en materia de adopción, donde podemos ver:

1. Se regula con más detalle la capacidad de los adoptantes y se incorpora una definición de la idoneidad para adoptar.

2. Se exige que la declaración de idoneidad de los adoptantes sea necesariamente previa a la propuesta que la entidad pública formula al juez. 
3. Para menores en situación de desamparo, no será necesario el asentimiento de los padres biológicos si transcurren dos años sin que hayan intentado revocar dicha situación.

4. Se regula ex novo, la guarda con fines de adopción. Esta previsión legal permitirá que con anterioridad a que la entidad pública formule la correspondiente propuesta al juez para la constitución de la adopción pueda iniciarse la convivencia provisional entre el menor y las personas consideras idóneas para tal adopción hasta que se dicte la oportuna resolución judicial, con el fin de evitar que el menor tenga que permanecer durante ese tiempo en un centro de protección o con otra familia.

5. Se introduce la figura de la adopción abierta, que posibilita que, una vez constituida la adopción, el adoptado pueda mantener con algún miembro de la familia de procedencia alguna forma de relación o contacto a través de visitas o de comunicaciones. Este régimen será acordado por el juez.

6. Se refuerza el derecho de acceso a los orígenes de las personas adoptadas, obligando a las entidades públicas a garantizarlo y mantener la información durante el plazo previsto en el Convenio Europeo de Adopción.

7. En materia de adopción internacional, entre otras modificaciones se clarifican el ámbito de aplicación de la ley y el concepto de adopción internacional, para incluir los casos de adopciones internacionales sin desplazamiento internacional de los menores; se deslindan las competencias entre la administración estatal y las autonómicas; se refuerzan las previsiones de garantía de las adopciones internacionales señalando que sólo podrán realizarse a través de las intermediación de organismos acreditados y en los casos de países signatarios del Convenio de La Haya; se detallan con mayor claridad las obligaciones de los adoptantes, tanto en fase preadoptiva como en fase postadoptiva, y se introducen importantes modificaciones en las normas de derecho internacional privado. $^{2}$

2 Gómez, Ana María, Las 10 claves de la reforma del sistema de protección a la infancia y a la adolescencia, Madrid, Wolters Kluwer, 2015, p. 3.

Esta obra está bajo una Licencia Creative Commons Atribución-NoComercial-SinDerivar 4.0 Internacional, IIJ-UNAM. Boletín Mexicano de Derecho Comparado, núm. 151, pp. 395-410. 


\section{LA ADOPCIÓN}

Se entiende por adopción o filiación adoptiva, el acto jurídico mediante el cual se crea un vínculo de parentesco entre dos personas, de tal forma que establece entre ellas una relación de paternidad y/o maternidad.

La adopción ha sufrido una larga transición a lo largo de su historia; de hecho, ha sido tratada de múltiples maneras, bien como un acto, como un negocio jurídico, e incluso como una institución. ${ }^{3}$ Actualmente la doctrina considera a la adopción como un acto jurídico, debido a que se constituye mediante resolución judicial, ${ }^{4}$ por la que se crea un vínculo jurídico entre adoptante y adoptado, que tiene los mismos efectos, derechos y obligaciones que el vínculo existente entre padres e hijos biológicos.

Los principios por los que se rige la adopción son: el interés superior del menor, para que en caso de conflicto con otro posible interés siempre prime el del menor, pues es la parte más vulnerable y débil; el principio de igualdad, o equiparación de efectos de las filiaciones y el principio de subsidiariedad de la adopción: prioridad de la familia de origen.

Las reformas introducidas por la Ley 26/2015, de 28 de julio, en materia de adopción.

\section{A. Las modificaciones del Código Civil español}

El Código Civil sufre una reforma sustancial en materia de adopción. Así, podemos ver en primer lugar que en el artículo 175 se establece la in-

3 Con anterioridad a la reforma del Código Civil de 1987 solía considerarse la adopción como un negocio jurídico de derecho de familia. A partir de la Ley 21/1987, del 11 de noviembre, no parece ello posible, ya que al manifestar que «la adopción se constituye por resolución judicial» y concederse amplio margen al juez para valorar su conveniencia, a pesar de que medien consentimiento de adoptante y adoptado, demuestra que el eje de la adopción ha dejado de ser el consentimiento de las partes (esencial para que pueda hablarse de negocio jurídico), que se ha convertido en simple presupuesto, dejando la primacía a la decisión del juez, que no queda vinculado por tal consentimiento, de Castro Lucini, Felipe. (1988) "Notas sobre la nueva regulación legal de la adopción", Revista de Derecho Inmobiliario, 1988, t. LXIV, p.158, en Artero Felipe, José Luis, "El elemento volitivo en la adopción", Dialnet, p. 3, disponible en: https://dialnet.unirioja.es/descarga/articulo/206414.pdf.

4 Como establece el artículo 176.1 CG: La adopción se constituirá por resolución judicial, que tendrá en cuenta siempre el interés del adoptando y la idoneidad del adoptante o adoptantes para el ejercicio de la patria potestad.

Esta obra está bajo una Licencia Creative Commons

Atribución-NoComercial-SinDerivar 4.0 Internacional, IIJ-UNAM.

Boletín Mexicano de Derecho Comparado, núm. 151, pp. 395-410. 
capacidad para adoptar de aquellos que no pudieran ser tutores, así como una edad mínima entre adoptante y adoptado; se establece también una diferencia de edad máxima para evitar que las discrepancias que existen en la normativa autonómica sobre edades máximas en la idoneidad provoquen distorsiones no deseables.

Así, el artículo 175.1 del Código Civil español dice

...la diferencia de edad entre adoptante y adoptando será de, al menos, dieciséis años y no podrá ser superior a cuarenta y cinco años, salvo en los casos previstos en el artículo 176.2. ${ }^{5}$ Cuando fueran dos los adoptantes, será suficiente con que uno de ellos no tenga esa diferencia máxima de edad con el adoptando. Si los futuros adoptantes están en disposición de adoptar grupos de hermanos o menores con necesidades especiales, la diferencia máxima de edad podrá ser superior.

La nueva redacción del artículo cambia los catorce años que debía de haber en su redacción anterior, a dieciséis años, adecuándose así al artículo 9o. del Convenio Europeo de Adopción, del 27 de noviembre de 2008, ${ }^{6}$ en el que se dice que "Deberá existir una diferencia de edad adecuada entre el adoptante y el menor, y en favor del interés superior del menor esta diferencia deberá ser preferentemente de al menos dieciséis años". Aunque en el Convenio sólo se dice "preferentemente", el legislador español lo ha establecido como la diferencia mínima de edad, siguiendo la recomendación del legislador europeo.

Esta reforma del artículo 175 del Código Civil deja intacta la edad mínima para adoptar, que sigue siendo veinticinco años, y cuando concurra

5 Que establece: "Para iniciar el expediente de adopción será necesaria la propuesta previa de la Entidad Pública a favor del adoptante o adoptantes que dicha Entidad Pública haya declarado idóneos para el ejercicio de la patria potestad. La declaración de idoneidad deberá ser previa a la propuesta.

No obstante, no se requerirá tal propuesta cuando en el adoptando concurra alguna de las circunstancias siguientes:

1a. Ser huérfano y pariente del adoptante en tercer grado por consanguinidad o afinidad.

2a. Ser hijo del cónyuge o de la persona unida al adoptante por análoga relación de afectividad a la conyugal.

3a. Llevar más de un año en guarda con fines de adopción o haber estado bajo tutela del adoptante por el mismo tiempo.

4a. Ser mayor de edad o menor emancipado".

6 Ratificado por España el 16 de julio de 2010.

Esta obra está bajo una Licencia Creative Commons Atribución-NoComercial-SinDerivar 4.0 Internacional, IIJ-UNAM. Boletín Mexicano de Derecho Comparado, núm. 151, pp. 395-410. 
una pareja, al menos uno de los adoptantes deberá tener esa edad mínima exigida. Se modifica en primer lugar la diferencia de edad entre adoptante y adoptado, que pasa de los catorce años exigidos anteriormente a dieciséis, y en segundo lugar, se establece por primera vez una edad máxima para adoptar, que será los 45 años, por lo que las personas mayores de 45 años no podrán adoptar bebés. No sé si acertadamente, teniendo en cuenta que en España y en Europa en general, que cada vez se retrasa más la maternidad, hay madres biológicas que superan los 45 años, la mayoría de las veces mediante medios de reproducción asistida, donde el legislador español guarda silencio.

Algunas comunidades autónomas con anterioridad a la entrada en vigor de la Ley 26/2015 habían legislado sobre la materia. Este era el caso, por ejemplo, de la comunidad de Madrid, ${ }^{7}$ que había establecido que tendrían prioridad para adoptar aquellas parejas que la diferencia de edad entre adoptante y adoptado no fuera superior a los cuarenta años de edad; en el caso de adopción por parejas, se consideraba la edad media entre ambos en el momento de la propuesta del menor.

El Código Civil hasta el momento no había fijado un límite máximo de edad como requisito de la familia adoptantes. Por un lado es más que lógico y razonable que el legislador establezca una serie de requisitos para cerciorarse en la medida de lo posible de que aquellas familias que desean adoptar tengan la capacidad necesaria para poder optar a esa adopción. Aunque debemos tener en cuenta que al haber entrado en esta materia el legislador, tendríamos que preguntarnos si entonces también tendría que fijar una edad máxima para las gestaciones de fecundaciones in vitro, cuando el óvulo y el esperma sea de donante, y los padres vayan a tener una diferencia de edad con su hijo superior a los 45 años.

Por otra parte, y como complemento de la capacidad de los adoptantes, el legislador español ha incorporado al artículo 176, CG, una definición de la idoneidad ${ }^{8}$ para adoptar, a fin de fortalecer la seguridad jurídica, y se incluye expresamente una previsión, de acuerdo con la cual no

7 Artículo 59.1. b) de la Ley 6/1995, del 28 de marzo, sobre Garantía de los derechos de la Infancia y la Adolescencia.

8 Así, en el punto 3 del artículo 176 CC dice: "Se entiende por idoneidad la capacidad, aptitud y motivación adecuadas para ejercer la responsabilidad parental, atendiendo a las necesidades de los menores a adoptar, y para asumir las peculiaridades, consecuencias y responsabilidades que conlleva la adopción". 
podrán ser declarados idóneos para la adopción los progenitores que se encuentren privados de la patria potestad o tengan suspendido su ejercicio, o hayan confiado la guarda de su hijo a una entidad pública. En relación con la actuación de la entidad pública en el procedimiento judicial de adopción, se producen dos importantes novedades. Por un lado, se exige que la declaración de idoneidad de los adoptantes sea necesariamente previa a la propuesta de adopción que la entidad pública formula al juez, ${ }^{9}$ cuestión que con anterioridad a esta ley no estaba claramente establecida, por lo que ahora el juez no podrá pronunciarse hasta que la entidad pública no emita su juicio. Esto ha sido criticado por la doctrina, que reiteradamente se viene quejando de la administrativización que está sufriendo el derecho civil, y dentro de él, de manera particular, la materia de protección de menores; ${ }^{10}$ y por otro, se modifican los supuestos en los que no es preceptiva la propuesta previa de la entidad pública de protección de menores para iniciar el expediente judicial de adopción. En concreto, el artículo 176.2.2o. dispone que "no se requerirá propuesta cuando el adoptado sea hijo del cónyuge o de la persona unida al adoptante por análoga relación afectividad", por lo que se equipara a las parejas de hecho con los matrimonios.

Otra importante novedad a destacar es el artículo 176 bis, que creo es un gran acierto por parte del legislador, gracias al cual se regula ex novo la guarda con fines de adopción. Esta previsión legal permitirá que con anterioridad a que la entidad pública formule la correspondiente propuesta al juez para la constitución de la adopción pueda iniciarse la convivencia provisional entre el menor y las personas consideradas idóneas para tal adopción hasta que se dicte la oportuna resolución judicial, con el fin de que el menor tenga que permanecer durante ese tiempo en un centro de protección o con otra familia.

9 Para emitir esa declaración de idoneidad, la entidad pública:

Requerirá una valoración psicosocial sobre la situación personal, familiar, relacional y social de los adoptantes.

Determinará si el adoptante o adoptantes tiene capacidad para establecer vínculos estables y seguros.

Valorará las habilidades educativas de los adoptantes y su aptitud para atender a un menos en función de sus singulares circunstancias.

10 Alberruche Díaz-Flores, Ma. Mercedes, "Novedades introducidas por la Ley 26/2015, del 28 de julio, de modificación del sistema de protección a la infancia y a la adolescencia, enmateria de adopción”, La Ley. Derecho de Familia, Madrid, La Ley, 13 de octubre de 2015, p. 6. 
La introducción de este artículo permite que el menor se vaya adaptando a la que probablemente vaya a ser su nueva familia, y, de esta manera, además se evita que aquél pase más tiempo en un centro de protección o que vaya a otra familia de acogida, lo que en cierta medida puede ser traumático para el menor. Además, esta guarda con fines de adopción sirve de periodo de adaptación del menor a la familia, así como de prueba de cómo puede ser esa convivencia.

Los guardadores con fines de adopción tendrán los mismos derechos y obligaciones que los acogedores familiares. ${ }^{11}$

El expediente de adopción comenzará con el escrito de propuesta de adopción formulada por la entidad pública o por la solicitud del adoptante cuando estuviera legitimado para ello, como hemos visto en el artículo 176.2, CG. Además, vemos que el artículo 177.1, CG, en su redacción de la Ley 26/2015, mantiene la necesidad de consentimiento, en presencia del juez, del adoptante y del adoptado mayor de doce años. El consentimiento de estas personas constituye un requisito imprescindible del acto constitutivo de la adopción.

El artículo 177.2, CC, regula los asentimientos a la adopción. ${ }^{12}$ En la redacción vigente, deben prestar su asentimiento a la adopción el cónyu-

11 Artículo 176 bis 1. 2.

12 Deberán asentir a la adopción:

1o. El cónyuge o persona unida al adoptante por análoga relación de afectividad a la conyugal salvo que medie separación o divorcio legal o ruptura de la pareja que conste fehacientemente, excepto en los supuestos en los que la adopción se vaya a formalizar de forma conjunta.

2o. Los progenitores del adoptando que no se hallare emancipado, a menos que estuvieran privados de la patria potestad por sentencia firme o incursos en causa legal para tal privación. Esta situación solo podrá apreciarse en el procedimiento judicial contradictorio que se tramitará conforme a la Ley de Enjuiciamiento Civil.

No será necesario el asentimiento cuando los que deban prestarlo se encuentren imposibilitados para ello, imposibilidad que se apreciará motivadamente en la resolución judicial que constituya la adopción.

Tampoco será necesario el asentimiento de los progenitores que tuvieren suspendida la patria potestad cuando hubieran transcurrido dos años desde la notificación de la declaración de situación de desamparo, en los términos previstos en el artículo 172.2, sin oposición a la misma o cuando, interpuesta en plazo, hubiera sido desestimada.

El asentimiento de la madre no podrá prestarse hasta que hayan transcurrido seis semanas desde el parto.

En las adopciones que exijan propuesta previa no se admitirá que el asentimiento de los progenitores se refiera a adoptantes determinados.

Esta obra está bajo una Licencia Creative Commons

Atribución-NoComercial-SinDerivar 4.0 Internacional, IIJ-UNAM.

Boletín Mexicano de Derecho Comparado, núm. 151, pp. 395-410. 
ge del adoptante y la persona unida al adoptante "por análoga relación afectiva a la conyugal". Igualmente, deberán prestar su asentimiento los padres del adoptando no emancipado con ciertas excepciones establecidas en el artículo 177.2.2o., CG.

Los asentimientos, a diferencia de los consentimientos - que se prestan por quienes serán parte en la adopción-, son emitidos por sujetos que no van a ser parte en la nueva relación de filiación que se constituye con la adopción, pero a quienes les afectarán de forma importante sus consecuencias. Al asentir estas personas, manifiestan su voluntad de admitir como conveniente la propuesta de adopción, sin que nadie, ni siquiera el juez, pueda sustituir su voluntad. No resultan vinculados jurídicamente como sujetos de la nueva relación que surgirá de la adopción, aunque ésta les afecta indirectamente. ${ }^{13}$

Esta nueva redacción del artículo 177, CG, no contempla las consecuencias que se pueden derivar de la negativa del asentimiento, supuesto especialmente problemático cuando se trata de los padres del adoptando, por lo que cabe mantener la opinión que ha venido sosteniendo la doctrina mayoritaria, que entiende que la adopción no puede constituirse válidamente contra la voluntad de quienes han de asentirla; por ello, si el juez decreta la adopción a pesar de la denegación de dicho asentimiento se producirá su nulidad. ${ }^{14}$ Si bien la jurisprudencia de las audiencias provinciales, en algunas resoluciones ha negado el valor vinculante de la oposición a la adopción de los padres del adoptando, en sentencias más recientes acepta el carácter vinculante de los asentimientos.

Según el artículo 177, CC, deberán ser oídos por el juez:

1. Los progenitores que no hayan sido privados de la patria potestad, cuando su asentimiento no fuera necesario. La confusa redacción de este precepto, que se mantiene, lleva a dos interpretaciones doctrinales del mismo, pues mientras algunos autores entienden que esta norma comprende dos casos: los padres que, sin estar privados de la patria potestad, estén incursos en alguna causa legal de privación, y los padres cuyo hijo ya está emancipado o es mayor de edad, otros autores mantienen que es obvio que aunque no lo seña-

13 Callejo Rodríguez, Carmen "El asentimiento a la adopción de los padres del adoptando no emancipado", La Ley. Derecho de Familia, núm. 9, 2016, p. 3.

14 Idem. 
le el precepto, tampoco será necesario el asentimiento, ni siquiera la audiencia, de los padres biológicos, en el supuesto de una adopción de un mayor de edad, ${ }^{15}$ lo cual entra dentro de toda lógica, al tener el adoptante la plena capacidad de obrar.

2. El tutor, y en su caso el guardador o guardadores, como novedad introducida por la Ley 26/2015, del 28 de julio, prevé que también sea oída la familia acogedora, lo que se refiere a los supuestos en que fueran distintos de los propuestos como adoptantes, pues entonces tendría que dar su consentimiento.

3. El adoptando menor de doce años, "de acuerdo con su edad y madurez", y no como sucedía, de acuerdo con la nueva redacción del artículo 177, y no ocurría a raíz de la Ley Orgánica 1/1996, del 15 de enero, que disponía que sólo debía ser oído si tenía suficiente juicio. ${ }^{16}$

Por otra parte, con el fin de dar coherencia al sistema, se señala que, sin perjuicio del derecho a ser oídos, no será necesario el asentimiento de los progenitores para la adopción cuando hubieran transcurrido dos años sin ejercitar acciones de revocación de la situación de desamparo o cuando habiéndose ejercitado, éstas hubieran sido desestimadas. Igualmente, se establece en el artículo 177, CG, que el asentimiento de la madre no podrá prestarse hasta que hayan transcurrido seis semanas desde el parto, en lugar de los treinta días ahora vigentes, dando así cumplimiento a lo dispuesto en el Convenio Europeo de Adopción hecho en Estrasburgo el 27 de noviembre de 2008, y ratificado por España. ${ }^{17}$

El legislador español acertadamente ha ampliado el tiempo que debe transcurrir desde el parto para que la madre asienta la adopción; así, se pasa de los treinta días establecidos en la redacción anterior del artículo 177, CG, a las seis semanas de la actual redacción.

Con esta ampliación del plazo para que la madre asienta desde el parto se persigue garantizar la emisión correcta del asentimiento por la

\footnotetext{
15 Ibidem, p. 5.

16 Idem.

17 Así, el artículo 5.5 del Convenio Europeo de Adopción dice: "El consentimiento de la madre para la adopción de su hijo sólo será válido cuando se preste después del nacimiento del mismo, al expirar el plazo prescrito por la ley, que no deberá ser inferior a seis semanas, o cuando no se hubiera especificado un plazo, en el momento en que, según la autoridad competente, la madre habría podido restablecerse adecuadamente de las consecuencias del alumbramiento".
}

Esta obra está bajo una Licencia Creative Commons

Atribución-NoComercial-SinDerivar 4.0 Internacional, IIJ-UNAM.

Boletín Mexicano de Derecho Comparado, núm. 151, pp. 395-410. 
madre, tras la recuperación tanto física como psíquica del parto, y con las facultades que le permitan ponderar las consecuencias de su declaración de voluntad con conciencia y libertad plena. Se trata, en suma, de una medida destinada a evitar decisiones precipitadas, que implícitamente responde al principio de prioridad de la propia familia. ${ }^{18}$ En definitiva, dotar de sosiego y libertad a la madre para prestarlo y evitar posibles invocaciones de nulidad del asentimiento prestado fundadas en la falta de capacidad natural para asentir en el periodo inmediatamente posterior al parto. En este sentido, la sentencia del Tribunal Supremo, del 21 de septiembre de 1999, establece que el asentimiento prestado con anterioridad a este periodo dará lugar a la nulidad de la adopción. ${ }^{19}$

Además de los motivos señalados anteriormente, ha destacado la doctrina, que esta reforma también está relacionada con el intento de evitar gestaciones de sustitución, en tanto la ampliación del plazo para que la madre pueda asentir sirva como medio de evitar maquinaciones para contratar con gestantes, lo que podría encubrir un tráfico de niños. ${ }^{20}$

En la Ley 26/2015 se incluye en el artículo 178 del Código Civil, como una importante novedad, la posibilidad de que, a pesar de que al constituirse la adopción se extingan los vínculos jurídicos entre el adoptado y su familia de procedencia, pueda mantenerse con algún miembro de ella alguna forma de relación o contacto a través de visitas o de comunicaciones, lo que podrá denominarse como "adopción

18 Pérez Álvarez, M. A., La nueva adopción, 1988, p. 186, en Artero Felipe, José Luis, "El elemento volitivo en la adopción", cit., p. 67.

19 Así, la sentencia del Tribunal Supremo 776/1999 del 21 de septiembre, anuló el consentimiento prestado para la adopción previamente al nacimiento del hijo. La madre, que estaba embarazada, en el octavo mes de gestación estimó que no podría hacerse cargo del hijo, y por ello lo atribuyó a la entidad pública, a los efectos de la guarda inmediata, acogimiento familiar y adopción; también prestó el asentimiento previo. La sentencia afirma que el asentimiento prestado por la madre resulta radicalmente nulo por su patente contradicción con una norma imperativa, y declara la nulidad de pleno derecho de la adopción de acuerdo con el artículo 6.3, CC. En este sentido, también la sentencia del Tribunal Supremo 728/2001, del 9 julio, declaró la nulidad por falta del asentimiento de la madre biológica en un procedimiento de adopción, puesto que el expediente se llevó a cabo de espaldas a la madre, a pesar de que ella pretendió personarse repetidas veces, sin conseguirlo. Admitió la acción de nulidad de la adopción "para el caso de que concurran vicios jurídicos insalvables, por sus efectos invalidantes".

20 Callejo Rodríguez, Carmen, "El asentimiento a la adopción de los padres del adoptando no emancipado", cit., p. 9. 
abierta". ${ }^{21}$ Para ello será necesario que en la resolución de constitución de la adopción así se acuerde por el juez, a propuesta de la entidad pública, previa valoración positiva en interés del menor (que es lo que siempre debe primar) por parte de los profesionales de esa entidad pública, y consentido por la familia adoptiva y el menor que tenga suficiente madurez y, en todo caso, si tuviera más de doce años.

Los profesionales de la entidad pública deberán apoyar a las partes y participar en el seguimiento de esa relación; tendrían que informar sobre la conveniencia o no de su permanencia en el tiempo, a partir de una valoración de los resultados y consecuencias que la misma tenga para el menor, como prioridad absoluta, más allá del interés que pueda suponer para los adoptantes y su familia de origen.

El juez, atendiendo al interés superior del menor, podrá acordar la modificación o finalización de esta relación. Los legitimados para solicitar la suspensión o supresión de las visitas, según el artículo 178.4, CC, serán las entidades públicas, la familia adoptiva, la familia de origen y el menor, si tuviera madurez suficiente y, en todo caso, si fuera mayor de doce años.

La oportunidad de introducir en nuestro ordenamiento jurídico esta figura, procedente básicamente de los países anglosajones, obedece a la búsqueda de alternativas consensuadas, familiares y permanentes, que permitan dotar de estabilidad familiar a algunos menores, especialmente los más mayores, cuya adopción presenta más dificultades. A través de la adopción abierta se flexibiliza la institución de la adopción, que posibilita que la familia de origen acepte mejor "la pérdida", y que el menor pueda beneficiarse de una vida estable en su familia adoptante, manteniendo vínculos con la familia de la que proviene, en especial con sus hermanos. ${ }^{22}$ Aunque probablemente pueda plantear algún problema con la familia adoptante, que pueden creer que su rol como padres se puede ver amenazado.

21 Así, el artículo 178.2 establece que "Por excepción subsistirán los vínculos jurídicos con la familia del progenitor que, según el caso, corresponda:

a) Cuando el adoptado sea hijo del cónyuge o de la persona unida al adoptante por análoga relación de afectividad a la conyugal, aunque el consorte o la pareja hubiera fallecido.

b) Cuando sólo uno de los progenitores haya sido legalmente determinado, siempre que tal efecto hubiera sido solicitado por el adoptante, el adoptado mayor de doce años y el progenitor cuyo vínculo haya de persistir".

22 Artículo 178.4. 2o., CG.

Esta obra está bajo una Licencia Creative Commons

Atribución-NoComercial-SinDerivar 4.0 Internacional, IIJ-UNAM.

Boletín Mexicano de Derecho Comparado, núm. 151, pp. 395-410. 
El artículo 178.4, CG, en su último párrafo, introducido tras la reforma, establece que es en la declaración de idoneidad donde deberá hacerse constar si las personas que se ofrecen a la adopción aceptarían adoptar a un menor que fuera a mantener la relación con la familia de origen.

Por último, el artículo 180, CG, ${ }^{23}$ refuerza el derecho de acceso a los orígenes de las personas adoptadas, al obligar a las entidades públicas a garantizarlo y mantener la información durante el plazo previsto en el Convenio Europeo de Adopción, y al resto de entidades a colaborar con las primeras y con el Ministerio Fiscal.

Para conseguir este fin, la Ley cambia la redacción del artículo 180.5, $\mathrm{CC}$, en el que se establece que

Las Entidades Públicas aseguran la conservación de la información de que dispongan relativa a los orígenes del menor, en particular la información respecto a la identidad de sus progenitores, así como la historia médica del

23 El artículo $180 \mathrm{CG}$ queda modificado de la siguiente manera:

"1. La adopción es irrevocable.

2. El Juez acordará la extinción de la adopción a petición de cualquiera de los progenitores que, sin culpa suya, no hubieren intervenido en el expediente en los términos expresados en el artículo 177. Será también necesario que la demanda se interponga dentro de los dos años siguientes a la adopción y que la extinción solicitada no perjudique gravemente al menor.

Si el adoptado fuere mayor de edad, la extinción de la adopción requerirá su consentimiento expreso.

3. La extinción de la adopción no es causa de pérdida de la nacionalidad ni de la vecindad civil adquiridas, ni alcanza a los efectos patrimoniales anteriormente producidos.

4. La determinación de la filiación que por naturaleza corresponda al adoptado no afecta a la adopción.

5. Las Entidades Públicas asegurarán la conservación de la información de que dispongan relativa a los orígenes del menor, en particular la información respecto a la identidad de sus progenitores, así como la historia médica del menor y de su familia, y se conservarán durante al menos cincuenta años con posterioridad al momento en que la adopción se haya hecho definitiva. La conservación se llevará a cabo a los solos efectos de que la persona adoptada pueda ejercitar el derecho al que se refiere el apartado siguiente.

6. Las personas adoptadas, alcanzada la mayoría de edad o durante su minoría de edad a través de sus representantes legales, tendrán derecho a conocer los datos sobre sus orígenes biológicos. Las Entidades Públicas, previa notificación a las personas afectadas, prestarán a través de sus servicios especializados el asesoramiento y la ayuda que precisen para hacer efectivo este derecho.

A estos efectos, cualquier entidad privada o pública tendrá obligación de facilitar a las Entidades Públicas y al Ministerio Fiscal, cuando les sean requeridos, los informes y antecedentes necesarios sobre el menor y su familia de origen".

Esta obra está bajo una Licencia Creative Commons Atribución-NoComercial-SinDerivar 4.0 Internacional, IIJ-UNAM. Boletín Mexicano de Derecho Comparado, núm. 151, pp. 395-410. 
menor y de su familia y se conservarán al menos cincuenta años con posterioridad al momento en que la adopción se haya hecho definitiva.

Por lo que tras la reforma del citado artículo los adoptados tendrán derecho a conocer los datos sobre sus orígenes biológicos, o bien por ellos mismos, alcanzada la mayoría de edad o a través de sus representantes legales, durante su minoría de edad. Para hacer efectivo este derecho, las entidades públicas, previa notificación a las personas afectadas, prestarán la ayuda y asesoramiento que sea preciso.

El beneficio del adoptado debe ser el principio fundamental por el que se debe regir la adopción, y se debe sobreponer a cualquier otro interés legitimo. Desde mi punto de vista, me parece un gran avance que el legislador español haya modificado el artículo 180 del Código Civil, al obligar a la entidades públicas a garantizar el derecho de acceso a los orígenes de las personas adoptadas. Así se refuerza y se reconoce el derecho a la identidad de los adoptados siempre que quieran tener acceso al ello, y, dentro del mismo, el derecho a conocer los orígenes biológicos, como manifestación "del libre desarrollo de la personalidad", inherente al ser humano, y del que no puede ser despojado. ${ }^{24}$

El reconocimiento del derecho a conocer los orígenes como derecho de la personalidad debe tener como límite el respeto a los derechos de los demás, y, especialmente, el derecho a la intimidad de las partes.

Asimismo, debe subrayarse la necesaria confidencialidad y reserva en las actuaciones de las administraciones públicas dirigidas al acceso a la información de los datos sobre la filiación biológica, ${ }^{25}$ habida cuenta que desde numerosas asociaciones de personas adoptadas se venía reclamando la tipificación al derecho a conocer los orígenes por el legislador español.

\section{B. Las modificaciones a la Ley de Adopción Internacional}

La vigente Ley modifica a la Ley 54/2007, del 28 de diciembre, de Adopción Internacionales, con dos objetivos básicos: primero, clarificar el

24 Díez Picazo, Luis y Gullón, Antonio, Sistema de derecho civil I, Madrid, Tecnos, 2003, p. 329, dice que "los derechos de la personalidad van siendo tipificados por los ordenamientos jurídicos en lugar de proclamar un único derecho de la personalidad".

25 AA.VV., Proyecto de investigación "Normativa sobre la búsqueda de orígenes de los adoptados en España y derecho comparado", El derecho del adoptado a conocer sus origenes, p. 117, disponible en: http://wrerw.fmyv.es/ci/es/Infancia/lgpi/13.pdf(consulta 28 de febrero de 2016).

Esta obra está bajo una Licencia Creative Commons

Atribución-NoComercial-SinDerivar 4.0 Internacional, IIJ-UNAM.

Boletín Mexicano de Derecho Comparado, núm. 151, pp. 395-410. 
ámbito de aplicación de la Ley, y segundo, definir el concepto de adopción internacional, como lo hace el Convenio de La Haya de 1983.

Se subraya el interés superior del menor como consideración fundamental en la adopción. Además, se refuerzan las previsiones de garantía de las adopciones internacionales, al señalar que sólo podrán realizarse a través de la intemediación de organismos acreditado, y se refuerzan los artículos sobre los controles sobre los beneficios financieros indebidos.

También se detallan con mayor claridad las obligaciones de los adoptantes, ${ }^{26}$ no sólo en la fase preadoptiva, sino en la postadoptiva, mediante el establecimiento de consecuencias jurídicas del incumplimiento de las obligaciones a las que los progenitores y las administraciones públicas están obligados respecto a los países de origen de los menores.

En las normas de derecho internacional se introducen importantes modificaciones, que básicamente responden a suprimir referencias a la modificación y revisión de la adopción, figuras jurídicas inexistentes en nuestro derecho, mejorar la regulación de la adopción consular circunscribiéndola a los supuestos en los que no se precisa propuesta de la entidad pública, establecer la imposibilidad de constituir adopciones de menores cuya ley nacional las prohíba, con alguna matización; asimismo, a modificar los presupuestos de reconocimiento de adopciones constituidas por las autoridades extranjeras, reformulando el control de la competencia internacional de la autoridad extranjera a través de la determinación de los vínculos razonables con el Estado extranjero cuyas autoridades la han constituido.

Por otra parte, se sustituye el presupuesto del control de la ley aplicable, ajeno al sistema español de reconocimiento de decisiones y resoluciones extranjeras, por el de la no contrariedad de la adopción constituida en el extranjero con el orden público español; concreta este concepto jurídico indeterminado en los casos de adopciones en las que el consentimiento de la familia de origen no ha existido, no ha sido informado o se ha obtenido mediante precio, para evitar que en este ámbito de la adopción internacional se produzcan supuestos de "niños robados"

\section{CONCLUSIONES}

La Ley 26/2015, del 28 de julio, de modificación del sistema de protección a la infancia y a la adolescencia, ha supuesto un transcendental avance en

26 Artículo 11. 
materia de adopción, donde se refuerzan los derechos de los adoptados y se establece claramente que aquello que debe primar es el interés del menor de edad; se regulan nuevas instituciones en nuestra legislación, como la adopción abierta, en la que el adoptado puede seguir manteniendo un determinado vínculo con su familia biológica, y se le reconoce el derecho a poder tener acceso a sus orígenes durante cincuenta años. Y se introduce $e x$ novo la guarda preadoptiva, para salvaguardar al menor de que tenga que pasar por un centro de acogida.

Además, respecto a la adopción internacional, se clarifica el ámbito de aplicación, así como su concepto.

Desde mi punto de vista, la mayoría de estas innovaciones por parte del legislador han sido bastante acertadas, aunque hasta que la Ley no lleve un mayor recorrido no sabremos si realmente son suficientes.

\section{BIBLIOGRAFÍA}

AA.VV., Proyecto de investigación "Normativa sobre la búsqueda de orígenes de los adoptados en España y derecho comparado", El derecho del adoptado a conocer sus origenes, disponible en: http://wrerw.fmyv.es/ci/es/Infancia/lgpi/13.pdf (consultado el 28 de febrero de 2016).

Alberruche DíAz-Flores, Ma. Mercedes, "Novedades introducidas por la Ley 26/2015, de 28 de julio, de modificación del sistema de protección a la infancia y a la adolescencia, enmateria de adopción", La Ley. Derecho de Familia, Madrid, La Ley, 13 de octubre de 2015.

ARTERO FeLIPE, José Luis, "El elemento volitivo en la adopción", Dialnet, disponible en: https://dialnet.unirioja.es/descarga/articulo/206414.pdf.

CAllejo Rodríguez, Carmen, "El asentimiento a la adopción de los padres del adoptando no emancipado", La Ley. Derecho de Familia, núm. 9, 2016.

Díez Picazo, Luis y Gullón, Antonio, Sistema de derecho civil I, Madrid, Tecnos, 2003.

Gómez, Ana María, Las 10 claves de la reforma del sistema de protección a la infancia y a la adolescencia, Madrid, Wolters Kluwer, 2015.

PÉrez Álvarez, M. A., La nueva adopción, 1988.

Esta obra está bajo una Licencia Creative Commons

Atribución-NoComercial-SinDerivar 4.0 Internacional, IIJ-UNAM.

Boletín Mexicano de Derecho Comparado, núm. 151, pp. 395-410. 